\title{
Correlation between religiosity and anxiety level in caregivers at Intensive Care Unit
}

I Gusti Agung Ayu Yulianti, Cokorda Bagus Jaya Lesmana, Luh Nyoman Alit Aryani

Department of Psychiatry, Faculty of Medicine Udayana University/Sanglah General Hospital Bali, Indonesia
Cite this article:

Yulianti IGAAY, Lesmana CBJ, Aryani LNA. Correlation Between Perimenopausal Syndromes and Depression in Nurses at Sanglah General Hospital. Journal of Clinical and Cultural Psychiatry. 2020; I (I): I8-2I.

Corresponding author:

Cokorda Bagus Jaya Lesmana Department of Psychiatry, Faculty of Medicine Udayana University/Sanglah General Hospital Jl. Kesehatan No I, Bali 80 I 4, Indonesia cokordabagus@unud.ac.id

\begin{abstract}
Background: Patients admitted to the ICU are Often in a state of uncertainty. This has an impact on the welfare of caregivers and other family members. This study aimed to determine the relationship between religiosity and the level of anxiety experienced by caregivers while accompanying patients in the ICU.

Materials and Method: This study is a non-experimental observational cross-sectional study with analytic correlational design. The research sample taken as many as 33 people as samples was carried out by consecutive sampling method.

Results: Religiosity is negatively related to mild to moderate anxiety $(R=-0.484, p>0.05)$. Religion is positively related to levels of moderate to severe anxiety $(R=0.402, p=0.038)$.

Conclusion: There is a negative relationship with the level of moderate strength between religiosity variables with mild to moderate levels of anxiety and there is a positive relationship between religiosity and moderate to very severe levels of anxiety in family caregiver ICU at Sanglah General Hospital in Denpasar.
\end{abstract}

Keywords: religiosity, anxiety level, ICU, caregiver

\section{Introduction}

Anxiety is an adaptive response that warned of the danger, which encourages a person to take action to address the threat and has the quality to save life. ${ }^{1}$ It is most commonly characterized as a diffuse fear, unpleasant, and vague. Anxious often accompanied by autonomic symptoms such as headache, sweating, palpitations, chest discomfort, bloating, and motor tension shown by an inability to sit or stand still for long periods of time. The constellation of specific symptoms that arise during the anxious tend to vary on each individual. ${ }^{2}$

Anxiety disorder is a mental disorder that most often occurs. In a systematic review of prevalence studies of 44 countries, the global prevalence of anxiety disorder is estimated at $7.3 \%$ (95\% CI 4.8 to 10.9 ), so one of 14 people around the world experience anxiety disorder at any given time and one of the nine the $11.6 \%$ (95\% CI 7.6 to 17.7$)$ experienced anxiety disorders every year. ${ }^{3}$ The prevalence of anxiety disorders in patients in the ICU caregiver is even higher. In a study conducted in ICUs in France, which assesses 920 family caregivers in 3-5 days after admission to the ICU found the prevalence of anxiety disorders $69 \%{ }^{4}$

Patients in the Intensive Care Unit (ICU) are generally at higher risk for death. ${ }^{5}$ Often the patient's family in particular caregiver. have a psychological and emotional disturbances are stronger. ${ }^{6}$ These feelings are not limited due to uncertainty as to whether the patient will survive, but 
also the extent to which the potential inability in the future. ${ }^{7}$ Experienced caregiver stress comes from many sources, including the onset of the critical condition of the disease, ICU environment, and the demands of their presence in the ICU and personal responsibility. ${ }^{8}$

The majority of studies have found religiosity has a positive effect and protective against anxiety disorders in ICU caregivers. ${ }^{9-11}$ There are several dimensions of religiosity, like the dimensions of belief (ideological dimension/religious belief), the dimensions of the practice of religion/worship (ritualistic dimension/religious practice), the dimensions of experience (experimental dimension/religious feeling), the dimensions of religious knowledge (intellectual dimension/religious knowledge), and the dimensions of the consequences (consequential dimension/religious effect). ${ }^{12}$ This study aimed to determine the relationship between religiosity and the level of anxiety experienced by caregivers while accompanying patients in the ICU.

\section{Material and Methods}

This is an analytic correlational research with cross-sectional design to determine the relationship of religiosity and the level of anxiety in caregivers of patients in the ICU. The main method used in this research is the subject of a questionnaire survey in the absence of treatment. Selection of subjects randomized in order to find the relationship between the independent variables (religiosity) and the dependent variable (the level of anxiety) to conduct an assessment at the same time. Subjects were patients in the ICU caregiver Sanglah Hospital who met the inclusion criteria and did not meet the exclusion criteria that have been set.

The questionnaire contained consent form after the explanation (informed consent), and the questioner BAI and religiosity Scale. Respondents who had given its written consent and then complete a questionnaire. The questionnaire has been filled in and returned to the researcher.

Anxiety levels were measured using questionnaires Anxiety Beck Inventory (BAI). BAI is one measure of the most widely used clinically. BAI showed high internal consistency. This instrument has 21 items that the 4 Likert scale, from 0 (not at all) to 3 (severe symptoms), with a total score of between 0 and $63 .{ }^{13-14}$ The scale of religiosity was measured by using a scale-based Glock and Stark already made modifications to the indigenous culture of Hinduism by Maharani. It consists of two parts, namely the scale Religiosity Scale I and II. ${ }^{15}$

This study has been getting information kelaiakan Ethics of the Research Ethics Commission in the Faculty of Medicine, University of Udayana / Sanglah General Hospital in Denpasar.

\section{Result}

A total of 33 samples that met the inclusion criteria and were included in the data analysis. The basic characteristics of respondents are presented in tables and narrative. Descriptive analysis in Table 1 obtained sample average 40.8 years old. Minimum age is 16 years and maximum age of 66 years. Samples were female as many as 19 people $(57.6 \%)$ while men numbered $14(42.4 \%)$.

Table 1 Distribution Frequency Caregiver characteristics Sanglah Hospital Patients in ICU

\begin{tabular}{lc}
\hline \multicolumn{1}{c}{ variables } & $\mathbf{N}=\mathbf{3 3}$ \\
\hline Age (mean years \pm SD) & $40.8 \pm 14.2$ \\
Gender & \\
Male & $14(42.4 \%)$ \\
Female & $19(57.6 \%)$ \\
Education & \\
SD & $7(21.2 \%)$ \\
SMP & $4(12.1 \%)$ \\
High School & $11(33.3 \%)$ \\
PT & $11(33.3 \%)$ \\
Family relationship & \\
Core & $29(87.9 \%)$ \\
Extended & $4(12.1 \%)$ \\
Has a job & \\
Yes & $20(60.6 \%)$ \\
No & $13(39.4 \%)$ \\
Post-surgery patients & \\
No & $10(30.3 \%)$ \\
Yes & $23(69.7 \%)$ \\
duration of ICU treatment & \\
$<1$ week & $25(75.8 \%)$ \\
1 week -1 month & $7(21.2 \%)$ \\
$>1$ month & $1(3.0 \%)$ \\
\hline
\end{tabular}

Most caregiver education is high school and college respectively $11(33.3 \%)$, and at least a junior secondary education by 4 people (12.1\%). Most caregivers who accompany patients is a core family of as many as 29 people (87.9\%), Based caregiver jobs more working, as many as 20 people $(60.6 \%)$, whereas that is not working as many as 13 people (39.4\%). Caregiver anxiety levels are: mild anxiety $(18.2 \%)$, moderate anxiety $(24.2 \%)$, and severe anxiety $11(33.3 \%)$, as shown in Table 2.

Table 1 Distribution Frequency rate of Religiosity and Anxiety

\begin{tabular}{lc}
\hline Variables & $\mathbf{N}=\mathbf{3 3}(\mathbf{\%})$ \\
Religiosity & \\
Moderate & $1(3.0)$ \\
High & $32(97.0)$ \\
Anxiety level & \\
Light & $6(18.2)$ \\
Moderate & $8(24.2)$ \\
Severe & $11(33.3)$ \\
\hline
\end{tabular}

\section{Discussion}

Based on the results of patients in the ICU caregiver Sanglah Hospital mostly have high religiosity that as many as 32 people $(97.0 \%)$, these results indicate that the caregiver has been very good in understanding and applying the teachings of his religion, so that the behavior that is raised in accordance with the teachings of religion adheres. Belief in God makes one hopeful. Often a person will be remembered creators and more frequently perform religious rituals in the face of disasters that exceed the strength limits. ${ }^{16}$

Analysis of religiosity relationship with the caregiver Anxiety Levels in ICU patients Sanglah Hospital in Denpasar, obtained Spearman's rho correlation coefficient (r) religiosity and anxiety level of $-0.484(p=0.079)$. We also obtained a significant positive correlation between religiosity and anxiety levels $(\mathrm{R}=0.402, \mathrm{p}=0.038)$. The higher the religiosity of a person, the higher the anxiety level. When 
a person experiences anxiety he tried to find a way to calm down, one to get closer to God, so that when subjected to severe anxiety people have become increasingly religious. Religiosity plays an important role in addressing critical illness for patients and families. A multi-center study found that patients be reassured after the presence of God with them in times of anxiety. ${ }^{17}$

One study reported a positive relationship between level of religiosity with moral anxiety in students in Riau, Indonesia. ${ }^{18}$ This means that the higher the level of religiosity of students, the higher the moral anxiety. Conversely the lower the level of religiosity of students will get low morale anxiety.

When people experience a feeling of living in uncertainty, helplessness and aimless when a loved one is in critical condition will arise anxiety. Under these conditions the things that often do is pray and surrender. Prayer can be an important source for the peace and comfort of heart. lean on power beyond human limits that anxiety becomes less. ${ }^{19}$

There are other factors that affect a person's level of anxiety, that religiosity is not a major factor in controlling the level of anxiety. This is demonstrated by the strength of the relationships in this study were included in the medium category.

\section{Conclusion}

There was a moderate correlation between religiosity and anxiety levels in ICU caregivers at Sanglah hospital.

\section{Acknowledgement}

The authors report no conflict of interests.

\section{Reference}

1. Craske MG and MB Stein. Anxiety. Lancet. 2016: 3048-59

2. BJ Sadock, VA Sadock, P. Ruiz. Anxiety disorder. Kaplan \& Sadock's synopsis of Psychiatry: Behavioral sciences / clinical psychiatry. $11^{\text {th }}$ ed. Philadelphia : Wolter Kluwer. 2015.pp. 387-391.

3. Kessler RC, AM Ruscio, K. Shear, et al. Epidemiology of anxiety disorders. Curr Top Behav Neurosci.2010:21-35.

4. F. Pochard, E. Azoulay, S. Chevret et al. Symptoms of anxiety and depression in family members of intensive care unit Patients: Ethical hypothesis regarding decision- making capacity. Critical Care Medicine.2001:1893-1897.

5. SM Stahl. Anxiety disorder and anxiolitic. Stahl's Essential psychopharmacology. $4^{\text {th }}$ ed. Cambridge: Cambridge Medicine, $2013: 388-419$.
6. M. Bolosi, v. Peritogiannis, P. Tzimas et al. Depressive and anxiety symptoms in relatives of the Intensive Care Unit Patients and the perceived need for support. J Neurosci Rural Pract. 2018: 522-8.

7. VC Chiang. Surviving a critical illness through mutually being there with each other: A grounded theory study. Intensive Crit. Care Nurs.2011 : 317-330.

8. TP Nelms, SK Eggenberger. The essence of the family critical illness experience and nurse-family meetings. Journal of Family Nursing. 2010:462-486. DOI: http://dx.doi.org/10.1177/1074840710386608 2010 .

9. JI Park, JP Hong, S. Park, MJ Cho. The relationship between religion and mental disorders in a Korean population. Psychiatry Investigation.2012;9 (1):29-35.

10. LM Chatters, KM Bullard, RJ Taylor et al. Religious participation and DSM-IV disorders among older African Americans: Findings from the National Survey of American Life Study. American Journal of geriatric Psychiatry. 2018:957-965.

11. FA Women. The difference in level of religiosity and Attitudes Toward Premarital Sex Between Student Enrolled in the School of Public and School-Based Religion. Scientific Journal. 2012;1:1-9.

12. FD Rosdian, Susandari. Study Regarding Diskriptif Religiosity in Troubled Students in high school PGII 2 Bandung. Proceedings of Psychology. Bandung, 2016.

13. AT Beck, N. Epstein and G, SRA Brown. An inventory for measuring clinical anxiety. Journal of Consulting and Clinical Psychology. 1988;56:893-897.

14. NK Maharani. Relationship Between Religiosity with Premarital Sexual Behavior In Teens (Hindu Religion). Thesis. Yogyakarta: Faculty of Psychology. Mercu Buana University, 2015.

15. E. Arsana. Religiosity Relationship with Adolescent Aggressiveness in Pesraman Gurukula Bangli. Thesis. Medical Education Program Specialist Psychiatry FK unud, 2017.

16. E. Dickinson. The Poems of Emily Dickinson. In Franklin RW, ed. Cambridge : MA, Harvard University Press, 1999:314 .

17. KM Piderman, DV Marek, SM Jenkins. Predicting Patients' expectations of hospital chaplains: a multisite survey. Mayo Clinic Proceed, 1002-10, 2010.

18. Satriani. The relationship between level of religiosity with moral anxiety Ushuludin student UIN Suska Riau. Thesis. Fak Psychology at State Islamic University Syarif Kasim Sultan Riau 2011.

19. C. Young, in spirituality, health, and healing, Medan, Bina media pioneer, 2007 , p. 9. 